\title{
Loading regimen required to rapidly achieve therapeutic trough plasma concentration of teicoplanin and evaluation of clinical features
}

This article was published in the following Dove Press journal:

Clinical Pharmacology:Advances and Applications

26 November 2012

Number of times this article has been viewed

\author{
Masafumi Seki ${ }^{1, *}$ \\ Kaori Yabuno ${ }^{1,2, *}$ \\ Koji Miyawaki ${ }^{1,2}$ \\ Yoshihiro Miwa² \\ Kazunori Tomono' \\ 'Division of Infection Control and \\ Prevention, ${ }^{2}$ Department of Pharmacy, \\ Osaka University Hospital, Suita, \\ Osaka, Japan \\ *These authors contributed equally \\ to this work
}

Background: A trough concentration of $>20 \mathrm{mg} / \mathrm{L}$ is considered the optimal dosage of teicoplanin required to ensure early therapeutic effects against methicillin-resistant Staphylococcus aureus (MRSA) infections including those in patients who develop febrile neutropenia after chemotherapy. This study determines appropriate initial doses during the first 2 days of administration and evaluates the therapeutic target teicoplanin trough concentration.

Method: A 2-day regimen was evaluated in patients treated with $600 \mathrm{mg}$ and $1200 \mathrm{mg}$ or $1200 \mathrm{mg}$ and $600 \mathrm{mg}$ (total $1800 \mathrm{mg}$, Group 1), $800 \mathrm{mg}$ and $800 \mathrm{mg}$ (total $1600 \mathrm{mg}$, Group 2), and $800 \mathrm{mg}$ and $400 \mathrm{mg}$ (total $1200 \mathrm{mg}$, Group 3) of teicoplanin on Days 1 and 2, respectively. We also compared the efficiency and adverse effects at trough concentrations of $15-20 \mathrm{mg} / \mathrm{L}$ (Group A, $\mathrm{n}=28$ ) with $>20 \mathrm{mg} / \mathrm{L}$ (Group B, $\mathrm{n}=27$ ) of teicoplanin, and also compared them with those on the similar concentrations of vancomycin (Groups $\mathrm{C}$ and $\mathrm{D}, \mathrm{n}=50$ and 34, respectively).

Results: The mean trough concentrations of teicoplanin on Days 4 or 5 were 22.2, 17.5, and $16.2 \mathrm{mg} / \mathrm{L}$ in Groups 1, 2, and 3, respectively. The clinical efficiency was $85.7 \%, 81.5 \%, 92.0 \%$, and $91.5 \%$, in Groups A, B, C, and D, respectively. The rates of adverse effects were not high in teicoplanin (nephrotoxicity, 7.1\% and 3.7\%, and hepatotoxicity, $14.3 \%$ and $11.1 \%$ in Groups A and $\mathrm{B}$, respectively). However, more adverse effects tended to arise in patients who received vancomycin in nephrotoxicity ( $14.0 \%$ and $11.8 \%$, in Groups $\mathrm{C}$ and $\mathrm{D}$, respectively).

Conclusion: These results suggest that the 2-day regimens with total $1800 \mathrm{mg}$ achieved the most effective therapeutic trough plasma concentration of teicoplanin $(20 \mathrm{mg} / \mathrm{L})$. However, $15-20 \mathrm{mg} / \mathrm{L}$ might also be an effective trough target for initial teicoplanin treatment. These teicoplanin regimens might be safer in terms of renal function than vancomycin.

Keywords: therapeutic drug monitoring, pharmacokinetics and pharmacodynamics, Staphylococcus aureus, MRSA, dosing regimen, adverse effect

\section{Introduction}

Teicoplanin is a glycopeptide antibiotic that has been extensively evaluated as a treatment for extremely invasive infection caused by Gram-positive bacteria., ${ }^{1,2}$ An initial teicoplanin loading procedure has been recommended to promptly achieve the optimal serum concentration.

Recent reports have recommended that therapeutic drug monitoring (TDM) should be used to maintain adequate serum trough concentrations. ${ }^{2,3}$ Although a teicoplanin trough concentration of $10 \mathrm{mg} / \mathrm{L}$ is generally accepted as the standard of care, a trough concentration of $>20 \mathrm{mg} / \mathrm{L}$ is currently recommended for some extreme situations, such as treating Staphylococcus aureus endocarditis, and bone or prosthetic infections. ${ }^{1,2}$
Correspondence: Masafumi Seki Division of Infection Control and Prevention, Osaka University Hospital, 2-I5 Yamadaoka, Suita, Osaka 565-087I, Japan

Tel +8I 668795093

Fax $+8 \mid 668795094$

Email seki@hp-infect.med.osaka-u.ac.jp 
A retrospective study found that favorable clinical outcomes of $S$. aureus-related deep infections treated with teicoplanin are associated with trough concentration values of $>20 \mathrm{mg} / \mathrm{L} .^{3,4}$ Weinbren and Struthers, commenting on possible causes of the emergence of methicillin-resistant $S$. aureus with reduced susceptibility during teicoplanin therapy, proposed that currently recommended dosages of teicoplanin should be increased. ${ }^{5}$ Targeting a trough concentration of $20 \mathrm{mg} / \mathrm{L}$ might help to treat $S$. aureus septicemia, particularly when less susceptible microorganisms have a minimum inhibitory concentration (MIC) close to the breakpoint for teicoplanin. Although no evidence has yet indicated MIC 'creep' in a teicoplanin regimen, an alternative therapeutic regimen to achieve a higher teicoplanin trough concentration of $15 \mathrm{mg} / \mathrm{L}$ should also be considered. ${ }^{1,2,6-8}$

Here, we created a teicoplanin regimen that achieved a target trough concentration of $>20 \mathrm{mg} / \mathrm{L}$ in patients and retrospectively evaluated its efficacy and toxicity at different concentrations.

\section{Materials and methods \\ Patients}

This study was carried out at Osaka University Hospital, Japan. This 1076-bed, teaching and academic hospital provides tertiary and advanced medical care. We used an electronic record and ordering system to investigate patients over 16 years of age who were admitted to our hospital between January 2009 and December 2011 under diagnoses of methicillin-resistant S. aureus, methicillin-resistant coagulase-negative staphylococci, ampicillin-resistant enterococci bacteremia, or teicoplaninsusceptible pathogens. We also included patients diagnosed with febrile neutropenia, who were ineligible for empirical antimicrobial therapy if the neutropenia had persisted at $<500$ cells $/ \mathrm{mm}^{3}$ for $>5$ days, and if they had fever of unknown origin at $>38.5^{\circ} \mathrm{C}$ on one occasion or $>38^{\circ} \mathrm{C}$ on at least two occasions. ${ }^{9}$
Demographics and laboratory markers of inflammation, renal, and hepatic function namely, C-reactive protein (CRP), alanine aminotransferase (ALT), aspartate aminotransferase (AST), creatinine clearance (CLcr), and total bilirubin were obtained from electronic medical records.

All patients or relatives provided written, informed consent to participate in this study, which was approved by the Research Ethics Committee of Osaka University Hospital.

\section{Treatment regimen and measurement of trough concentration}

Three treatment regimens were evaluated prospectively (Table 1). Group 1 was administered with $600 \mathrm{mg}$ of teicoplanin twice on Day 1 and once on Day 2. A 2-day regimen comprising a loading dose of $600 \mathrm{mg}$ on the afternoon of Day 1 and $600 \mathrm{mg}$ twice on Day 2 was also included (Group 1). This regimen was administered to patients whose laboratory data were completed in the afternoon, and who received teicoplanin in the evening. The total doses $(1800 \mathrm{mg})$ were identical. The 2-day regimen of a 400-mg loading twice on Days 1 and 2 (total $1600 \mathrm{mg}$ ) was administered to Group 2. The 1-day regimen (standard regimen) of $2 \times 400$-mg loading doses on Day 1 followed by $400 \mathrm{mg}$ on Day 2 (total $1200 \mathrm{mg}$ ) was administered to Group 3.

Teicoplanin target trough concentration samples were obtained just before administration on Days 4 or 5 . Achieving a trough concentration of $15-20 \mathrm{mg} / \mathrm{L}$ or $>20 \mathrm{mg} / \mathrm{L}$ was evaluated in each group. The dosing regimen after Day 4 was adjusted according to the trough concentration data.

Trough concentration of teicoplanin was measured by Fluorescence Polarization Immunoassay (FPIA; Tagocid TDM kit-IBL, Immuno-Biological Laboratories Co, Ltd, Fujioka, Japan).

\section{Clinical efficiency and adverse effects at each trough concentration}

We retrospectively compared the efficiency and adverse effects of $15-20 \mathrm{mg} / \mathrm{L}$ and $>20 \mathrm{mg} / \mathrm{L}$ trough concentrations

Table I Dose of teicoplanin administration to the patients

\begin{tabular}{|c|c|c|c|c|c|}
\hline & $\begin{array}{l}\text { Administration example } \\
\text { (Ist-2nd day: total doses on } 2 \text { days) ( } \mathrm{mg} \text { ) }\end{array}$ & $\begin{array}{l}\text { Age } \\
\text { (years) }\end{array}$ & $\begin{array}{l}\text { Weight } \\
\text { (kg) }\end{array}$ & $\begin{array}{l}\text { Albumin } \\
\text { (mg/L) }\end{array}$ & $\begin{array}{l}\text { Creatinine } \\
(\mathrm{mg} / \mathrm{L})\end{array}$ \\
\hline $\begin{array}{l}\text { Group I } \\
(\mathrm{n}=\mathrm{II})\end{array}$ & $\begin{array}{l}1200-600(1800) \\
600-1200(1800)\end{array}$ & $42.0 \pm 10.8$ & $53.7 \pm 5.7$ & $3.4 \pm 0.6$ & $0.6 \pm 0.2$ \\
\hline $\begin{array}{l}\text { Group } 2 \\
(\mathrm{n}=6)\end{array}$ & $800-800(1600)$ & $42.3 \pm 24.5$ & $48.8 \pm 7.9$ & $2.9 \pm 0.8$ & $0.6 \pm 0.2$ \\
\hline $\begin{array}{l}\text { Group } 3 \\
(\mathrm{n}=\mathrm{II})\end{array}$ & $800-400(1200)$ & $53.5 \pm 15.1$ & $49.0 \pm 11.0$ & $3.0 \pm 0.5$ & $\mathrm{I} . \mathrm{I} \pm 0.7$ \\
\hline
\end{tabular}

Note: Age, weight, albumin, and creatinine were expressed as mean \pm standard deviation. 
of teicoplanin (Groups A and B, n = 28 and 27, respectively) and vancomycin (Groups $\mathrm{C}$ and $\mathrm{D}, \mathrm{n}=50$ and 34, respectively) to confirm the clinical safety of teicoplanin. We collected not only the cases which showed these trough concentrations at first measurement at Days 4-5 in teicoplanin and Days 3-4 in vancomycin, but also the cases which showed these trough concentrations at other points, such as Day 7 and Day 10.

Clinical efficacy was evaluated by improvement of body temperature and CRP as therapeutic responses, and clinical evaluations were performed 7-10 days after the final dose as previously reported. ${ }^{6,7}$

The adverse effects of nephrotoxicity and hepatotoxicity were also evaluated on the day that teicoplanin therapy was completed and 7-10 days after the last dose. Nephrotoxicity was defined as a serum creatinine increase of $0.5 \mathrm{mg} / \mathrm{dL}$ or $50 \%$ from baseline. ${ }^{6,10}$ Hepatotoxicity was defined as AST or ALT that was three-fold the upper limit of normal (ULN; AST: 13-33 IU/L, ALT: 8-42 IU/L). If the AST or ALT baseline was abnormal, hepatotoxicity was defined as AST or ALT three times increased from the baseline values. ${ }^{6,11}$

\section{Statistical analysis}

Statistical analysis of the survey data was of a descriptive nature, where continuous variables are shown as summarized means and standard deviation (SD).

Data were statistically analyzed using a parametric, paired or unpaired Student's $t$-test as appropriate, or the nonparametric Mann-Whitney rank-sum test, for normally or non-normally distributed data, respectively. For multiple comparison, we performed parametric tests, including TukeyKrammer's method, Scheffe's F-test, and Bonferroni-Dunn's method, and nonparametric Steel-Dwass' method, Steel's method, and Shirley-William's method, respectively. The clinical efficacy and adverse effects were also analyzed using Fisher's exact test and nonparametric Kruskal-Wallis test.

A value of $P<0.05$ was considered to indicate statistical significance.

\section{Results}

\section{Achievement of target trough concentration}

Table 1 shows the characteristics of the 28 patients in the study of the teicoplanin loading regimen (Groups 1, 2, and 3, $\mathrm{n}=11,6$, and 11, respectively). Age, body weight, serum albumin, and serum creatinine values were similar among the groups, and no statistically significant differences were found regarding the effects $(P=0.50)$. Maintenance therapy was administered at $400 \mathrm{mg}$ once per day in most of the cases, and the duration of maintenance therapy was also similar within the group. Most patients were diagnosed with febrile neutropenia and the numbers of patients with various types of infection were similar among the three groups (data not shown).

The mean trough concentration in Groups 1, 2, and 3 were $22.2 \pm 6.6,17.5 \pm 5.3$, and $16.2 \pm 3.6 \mathrm{mg} / \mathrm{L}$, respectively (Figure 1). The $>20 \mathrm{mg} / \mathrm{L}$ trough concentration was achieved only in Group 1.

\section{Clinical efficiency and adverse effects}

Table 2 shows the results of retrospective analysis for the rates of treatment success and adverse effects in each trough concentration of teicoplanin and vancomycin. The success rates were $85.7 \%, 81.5 \%, 92.0 \%$, and $91.2 \%$ in Groups $A$, $\mathrm{B}, \mathrm{C}$, and $\mathrm{D}$, respectively $(P=0.50)$, with no significant differences between Groups A and B that achieved 15-20 mg/L and $>20 \mathrm{mg} / \mathrm{L}$ of teicoplanin, respectively $(P=0.35)$, and between Groups C and D that achieved 15-20 mg/L and $>20 \mathrm{mg} / \mathrm{L}$ of vancomycin, respectively $(P=0.45)$. The loading regimen of teicoplanin in Groups $\mathrm{A}$ and $\mathrm{B}$ was also not significantly different $(P=0.50)$.

The incidences of nephrotoxicity (Group A vs B, 7.1\% vs $3.7 \%$ ) and hepatotoxicity (Group A vs B, 14.2\% vs 11.1\%) did not significantly differ among the teicoplanin groups $(P=0.57)$. However, the groups treated with vancomycin tended to develop nephrotoxicity more frequently (Group C vs D, 14.0\% vs 11.7\%), compared with the groups

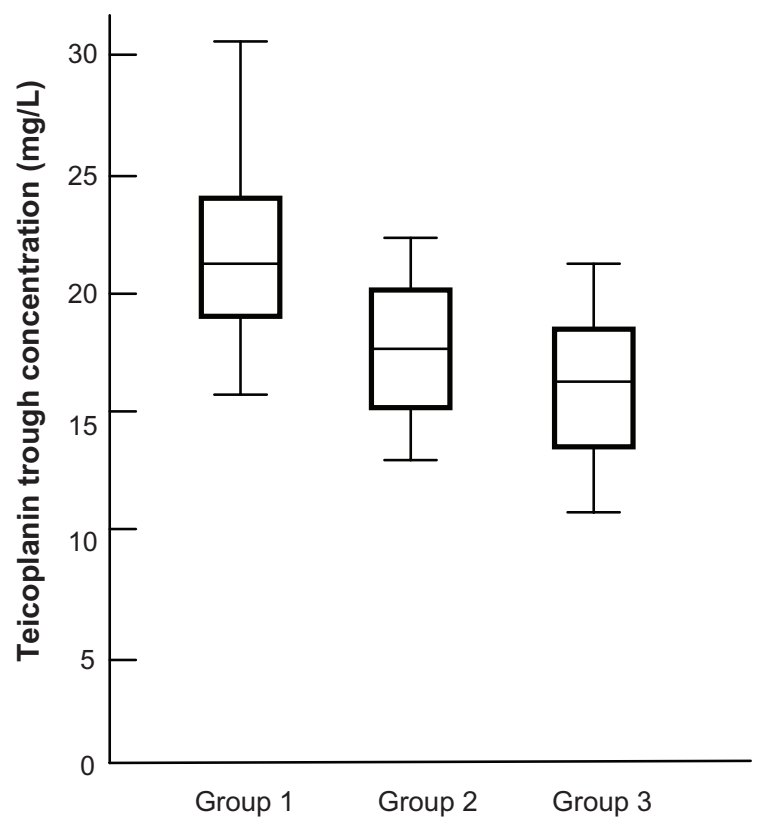

Figure I Teicoplanin trough concentrations. Note: Data are expressed as means \pm standard deviation. 
Table 2 Treatment success and adverse effects rates in each group

\begin{tabular}{|c|c|c|c|c|}
\hline & $\begin{array}{l}\text { Group A } \\
\text { TEIC: I5-20 mg/L } \\
(n=28)\end{array}$ & $\begin{array}{l}\text { Group B } \\
\text { TEIC: }>20 \mathrm{mg} / \mathrm{L} \\
(\mathrm{n}=27)\end{array}$ & $\begin{array}{l}\text { Group C } \\
\text { VCM: I5-20 mg/L } \\
(n=50)\end{array}$ & $\begin{array}{l}\text { Group D } \\
\text { VCM: }>20 \mathrm{mg} / \mathrm{L} \\
(\mathrm{n}=34)\end{array}$ \\
\hline \multicolumn{5}{|c|}{ Treatment response } \\
\hline Success & $24 / 28$ (85.7\%) & $22 / 27$ (81.5\%) & $46 / 50(92.0 \%)$ & $3 \mathrm{I} / 34$ (9I.2\%) \\
\hline \multicolumn{5}{|l|}{ Adverse effects } \\
\hline Nephrotoxicity & $2 / 28(7.1 \%)$ & $\mathrm{I} / 27(3.7 \%)$ & $7 / 50$ (14.0\%) & $4 / 34$ (II.8\%) \\
\hline Hepatotoxicity & 4/28 (I4.3\%) & 3/27 (II.1\%) & $9 / 50(18.0 \%)$ & $7 / 34$ (20.6\%) \\
\hline
\end{tabular}

Abbreviations: TEIC, teicoplanin; VCM, vancomycin.

treated with teicoplanin (Group B [teicoplanin $>20 \mathrm{mg} / \mathrm{L}$ ] and C [vancomycin 15-20 mg/L], $P=0.08$, respectively).

The incidence of hepatotoxicity in the groups treated with vancomycin (Group C vs D, $18.0 \%$ vs $20.6 \%$ ) was similar to that of the groups treated with teicoplanin $(P=0.50)$.

\section{Discussion}

Recent recommendations suggest that the trough concentration of teicoplanin should be maintained at $>20 \mathrm{mg} / \mathrm{L}$ to treat severe infection. ${ }^{1,2,5,7-9,12} \mathrm{~A}$ high-dose regimen of teicoplanin for the first 3-4 days can achieve a higher target trough concentration. ${ }^{6,7,9,12-14}$ Brink et al assessed the standard teicoplanin regimen comprising $6 \mathrm{mg} / \mathrm{kg}$ every 12 hours on Day 1 followed by $6 \mathrm{mg} / \mathrm{kg}$ daily thereafter with a high-dose regimen comprising $6 \mathrm{mg} / \mathrm{kg}$ every 12 hours for 4 days among patients with suspected or confirmed Gram-positive infections. ${ }^{8}$ The mean trough concentration values on Day 4 were 19.1 and $9.6 \mathrm{mg} / \mathrm{L}$ for the high-dose and standard regimens, respectively.

Here, we found that only the 1200 - and 600- or 600- and 1200-mg regimens (Group 1; total $1800 \mathrm{mg}$ regimen) could achieve a teicoplanin trough concentration of $>20 \mathrm{mg} / \mathrm{L}$. The 800- and 800- (Group 2; total $1600 \mathrm{mg}$ regimen) and 800- and 400- (Group 3; total $1200 \mathrm{mg}$ regimen) $\mathrm{mg}$ regimens also achieved a sufficient trough concentration of $15-20 \mathrm{mg} / \mathrm{L}$, but the Group 1 regimen might confer the most advantages for rapidly achieving a trough concentration of $>20 \mathrm{mg} / \mathrm{L}$. These data suggest that a total dose of $1800 \mathrm{mg}$ might be needed to achieve this trough target. Furthermore, the 600and 1200-mg regimen could be used for Group 1 if laboratory data are provided in the afternoon/evening as teicoplanin administration twice before midnight might be onerous. This regimen is also more practical than administering two doses on the day of admission.

It has been reported that the trough concentration of teicoplanin achieved by the standard regimen (loading dose of $800 \mathrm{mg}$ on Day 1, followed by maintenance doses of $400 \mathrm{mg}$ ) remains $<10-15 \mathrm{mg} / \mathrm{L} .{ }^{15}$ Pea et al also compared the standard ( $400 \mathrm{mg}$ every 12 hours on Day 1 followed by $400 \mathrm{mg}$ daily) with high-dose (800 and $400 \mathrm{mg}$ at an interval of 12 hours on Day 1, 600 and $400 \mathrm{mg}$ at an interval of 12 hours on Day 2, followed by $400 \mathrm{mg}$ every 12 hours) regimens in adult patients (CLcr $<50 \mathrm{~mL} /$ minute) with acute leukemia who developed febrile neutropenia after chemotherapy. ${ }^{9}$ The trough concentration of the high-dose regimen at 72 hours exceeded $20 \mathrm{mg} / \mathrm{L}$ in 10 of 22 of their patients, and renal function was not significantly impaired in any of them. These data also supported the necessity and safety of the higher dose at loading in the use of teicoplanin.

It has been suggested that the risk of nephrotoxicity is lower with teicoplanin than vancomycin,,${ }^{1,2,16,17}$ but high-dose teicoplanin tends to cause hepatotoxicity. ${ }^{18}$ Therefore, we should confirm teicoplanin safety although we investigated the loading dose regimen to achieve $>20 \mathrm{mg} / \mathrm{L}$ trough concentration in the current study (Group A-C).

We retrospectively evaluated the efficacy and adverse effects between groups treated with teicoplanin and vancomycin at target trough concentrations of $15-20 \mathrm{mg} / \mathrm{L}$ and $>20 \mathrm{mg} / \mathrm{L}$. Success rates were acceptable and similar among the four groups, indicating that the clinical efficacy of teicoplanin and vancomycin are essentially equal. Among our patients who received teicoplanin, $60 \%$ had febrile neutropenia (data not shown), and teicoplanin trough concentrations of $15-20 \mathrm{mg} / \mathrm{L}$ were usually as effective as $>20 \mathrm{mg} / \mathrm{L}$.

The incidences of nephrotoxicity and hepatotoxicity did not significantly differ between the 2-day loading regimens among the groups in this study. We also could not find any difference of loading regimen between the groups with $15-20 \mathrm{mg} / \mathrm{L}$ and $>20 \mathrm{mg} / \mathrm{L}$ in this retrospective analysis. Most of these cases were treated by standard (low dose) regimen: ex 400-400 mg or 200-200 mg on Day 1 only. The differences of these achieved trough concentrations might be affected by patients' clinical characteristics at admission, including complications. Further studies are required.

Although hepatotoxicity occurred at similar rates in both the teicoplanin and vancomycin groups, the incidence of nephrotoxicity was only $7.1 \%$ and $3.7 \%$ at trough 
concentrations of $15-20 \mathrm{mg} / \mathrm{L}$ and $>20 \mathrm{mg} / \mathrm{L}$, respectively, in patients treated with teicoplanin, compared with vancomycin (14.0\% and $11.8 \%$, respectively).

Mimoz et al assessed a high-dose teicoplanin regimen (12 mg/kg every 12 hours for two consecutive days, followed by $12 \mathrm{mg} / \mathrm{kg}$ daily) in patients (CLcr $>60 \mathrm{~mL} / \mathrm{minute}$ ) with ventilator-associated pneumonia. ${ }^{14}$ The mean trough concentration on Day 4 was $15.9 \mathrm{mg} / \mathrm{L}$, and no serious clinical or clinically significant biological adverse effects developed. Creatinine values returned to baseline within 2 weeks after discontinuing teicoplanin in one of two patients in that study. In addition, Frye et al reported that decrease of platelets as an adverse effect was found at trough concentration $>40 \mathrm{mg} / \mathrm{L},{ }^{19}$ and renal dysfunction was reported at trough concentration $>60 \mathrm{mg} / \mathrm{L}$ in teicoplanin use. ${ }^{20}$ These results suggest that the risk of adverse effects, especially renal impairment may be lower with teicoplanin than with vancomycin.

In conclusion, a 2-day regimen which administered total $1800 \mathrm{mg}$ (1200- and 600- or 600- and 1200-mg) of teicoplanin was practical and rapidly achieved a therapeutic trough plasma concentration of $>20 \mathrm{mg} / \mathrm{L}$. However, 15-20 mg/L may also be a sufficient initial teicoplanin trough target with which to treat febrile neutropenia. These teicoplanin regimens may be safer in terms of renal function than vancomycin, while offering similar clinical efficacy.

\section{Disclosure}

The authors report no conflicts of interest in this work.

\section{References}

1. Gemmell CG, Edwards DI, Fraise AP, Gould FK, Ridgway GL, Warren RE; Joint Working Party of the British Society for Joint Working Party of the British Society for Antimicrobial Chemotherapy, Hospital Infection Society and Infection Control Nurses Association. Guidelines for the prophylaxis and treatment of methicillin-resistant Staphylococcus aureus (MRSA) infections in the UK. JAntimicrob Chemother. 2006;57: 589-608.

2. Liu C, Bayer A, Cosgrove SE, et al. Clinical practice guidelines by the infectious diseases society of america for the treatment of methicillinresistant Staphylococcus aureus infections in adults and children: executive summary. Clin Infect Dis. 2011;52:285-292.

3. MacGowan AP. Pharmacodynamics, pharmacokinetics, and therapeutic drug monitoring of glycopeptides. Ther Drug Monit. 1998;20: 473-477.

4. MacGowan AP, Bowker KE. Pharmacodynamics of antimicrobial agents and rationale for their dosing. J Chemother. 1997;9:64-73.

Clinical Pharmacology: Advances and Applications

\section{Publish your work in this journal}

Clinical Pharmacology: Advances and Applications is an international, peer-reviewed, open access journal publishing original research, reports, reviews and commentaries on all areas of drug experience in humans. The manuscript management system is completely online and includes a very quick and fair peer-review system, which is all easy to use.
5. Weinbren M, Struthers K. Emergence of Staphylococcus aureus (MRSA) with reduced susceptibility to teicoplanin during therapy. J Antimicrob Chemother. 2002;50:306-307.

6. Ueda T, Takesue Y, Nakajima K, et al. Evaluation of teicoplanin dosing designs to achieve a new target trough concentration. $J$ Infect Chemother. 2012;18:296-302.

7. Matsumoto K, Kanazawa N, Ikawa K, et al. Determination of teicoplanin trough concentration target and appropriate total dose during the first 3 days: a retrospective study in patients with MRSA infections. $J$ Infect Chemother. 2010;16:193-199.

8. Brink AJ, Richards GA, Cummins RR, et al. Recommendations to achieve rapid therapeutic teicoplanin plasma concentrations in adult hospitalised patients treated for sepsis. Int J Antimicrob Agents. 2008; 32:455-458.

9. Pea F, Viale P, Candoni A, et al. Teicoplanin in patients with acute leukaemia and febrile neutropenia: a special population benefiting from higher dosages. Clin Pharmacokinet. 2004;43:405-415.

10. Rybak M, Lomaestro B, Rotschafer JC, et al. Therapeutic monitoring of vancomycin in adult patients: a consensus review of the American Society of Health-System Pharmacists, the Infectious Diseases Society of America, and the Society of Infectious Diseases Pharmacists. Am J Health Syst Pharm. 2009;66:82-98.

11. Senior JR. Monitoring for hepatotoxicity: what is the predictive value of liver "function" tests? Clin Pharmacol Ther. 2009;85:331-334.

12. Wang JT, Liao HI, Wu Lin FL, Chang SC. Loading dose required to achieve rapid therapeutic teicoplanin trough plasma concentration in patients with multidrug-resistant gram-positive infections. Basic Clin Pharmacol Toxicol. 2012;110:416-420.

13. Lamont E, Seaton RA, Macpherson M, Semple L, Bell E, Thomson AH. Development of teicoplanin dosage guidelines for patients treated within an outpatient parenteral antibiotic therapy (OPAT) programme. J Antimicrob Chemother. 2009;64:181-187.

14. Mimoz O, Rolland D, Adoun M, et al. Steady-state trough serum and epithelial lining fluid concentrations of teicoplanin $12 \mathrm{mg} / \mathrm{kg}$ per day in patients with ventilator-associated pneumonia. Intensive Care Med. 2006;32:775-779.

15. Pea F, Brollo L, Viale P, Pavan F, Furlanut M. Teicoplanin therapeutic drug monitoring in critically ill patients: a retrospective study emphasizing the importance of a loading dose. JAntimicrob Chemother. 2003;51: 971-975.

16. Svetitsky S, Leibovici L, Paul M. Comparative efficacy and safety of vancomycin versus teicoplanin: systematic review and meta-analysis. Antimicrob Agents Chemother. 2009;53:4069-4079.

17. Van der Auwera P, Meunier F, Ibrahim S, Kaufman L, Derde MP, Tulkens PM. Pharmacodynamic parameters and toxicity of netilmicin ( 6 milligrams/kilogram/day) given once daily or in three divided doses to cancer patients with urinary tract infection. Antimicrob Agents Chemother. 1991;35:640-647.

18. Yoshida M, Matzno S, Namba H, Nishikata M, Matsuyama K. Statistical analysis of the adverse effects of glycopeptide antibiotics, based on pharmacokinetics and toxicokinetics (PK/TK). J Infect Chemother. 2006;12:114-118.

19. Frye RF, Job ML, Dretler RH, Rosenbaum BJ. Teicoplanin nephrotoxicity: first case report. Pharmacotherapy. 1992;12:240-242.

20. Wilson APR, Grunegerg R. Safety. In: Teicoplanin; The First Decade. Abingdon, UK: The Medicine Group (Education) Ltd; 1997:137-144.

\section{Dovepress}

Visit http://www.dovepress.com/testimonials.php to read real quotes from published authors. 